\title{
The physicochemical characteristics and the pollution level of Dayet Er-Roumi Lake in Morocco
}

\author{
Sara El Ghizi ${ }^{1,2,3, *}$, Nezha El Aadel ${ }^{2}$, Mohamed Sadik ${ }^{2}$, Mohammed El Bouch ${ }^{3}$, and Mustapha Hasnaoui ${ }^{1}$ \\ ${ }^{1}$ Environmental Engineering Team, Department of Biology. Faculty of Sciences and Techniques, Sultan Moulay Slimane \\ University. BP. 523, 23000 Beni Mellal, Morocco. \\ ${ }^{2}$ National Center for Hydrobiology and Fish Farming, Azrou. HCEFLCD, Morocco. \\ ${ }^{3}$ National Laboratory for Pollution Studies and Monitoring (LNESP), Rabat-Morocco.
}

\begin{abstract}
The management of natural surface water resources requires an understanding and knowledge of water quality. The Lake Dayet Er-Roumi (classified as a Site of Biological and Ecological Interest (SIBE)) is the only permanent continental lake of low altitude in Morocco, this international attraction site is subject to various sources of anthropogenic pollution, in addition to the effects of climate change (thermal variability, lack of precipitation, etc.). The objective of this work is to quantify and assess the quality of the waters lake, and its tributaries through Spatio-temporal monitoring of several physicochemical parameters during two seasons (winter and summer) of the year 2019. All the physicochemical analysis (such as temperature, hydrogen potential, electrical conductivity, dissolved oxygen, nitrates, orthophosphates, and chlorides) were carried out at 7 study stations (5 stations at lake level and 2 stations representing the tributaries). Statistical calculation of the data set revealed high concentrations of chlorides in both seasons and orthophosphates during the summer season, with average nitrate concentrations during the winter season. The results obtained show that the $\mathrm{pH}$ of the water is basic with a very high electrical conductivity showing a load of water in different minerals. These results greatly exceed the standards of fish water quality and surface water quality. They show that the lake Dayet ErRoumi is polluted. Strategies to limit the pollution of the lake must be implemented by decision-makers at all levels, in order to avoid several ecological problems (fish mortality for example).
\end{abstract}

\section{Introduction}

Water is an essential component of the environment, and it sustains life on earth. Wetlands (lakes, lagoons, etc.) are the planet's most important freshwater resources that offer numerous environmental, social, and economic benefits (support for biodiversity, providing water for irrigation and food via fish, tourism, and recreation).

The quality of surface water is more deteriorated by anthropogenic activities (domestic, industrial, and agricultural discharges, etc.) than natural processes (weathering and soil erosion). Water quality is constituted of various abiotic and biotic factors associated with the ecosystem. The Safeguarding of a healthy ecosystem depends on several physicochemical properties of the water and also on biological diversity. Abiotic and biotic factors of the lake ecosystem are interdependent and the change of abiotic factors frequently affects the biotic factors that modify their biodiversity.

The abiotic factors of water (such as temperature, conductivity, dissolved oxygen, $\mathrm{pH}$, alkalinity, phosphate, nitrate, etc.) govern highly the aquatic life, these abiotic factors are generally the driving forces of the environment and the influencers of the well-being, and as well of the distribution of organisms and the ecosystem's functioning [1]. Therefore, by studying abiotic parameters, the monitoring of water surface quality makes it possible to assess the state of an aquatic ecosystem [2].

Environmental pollution, mainly freshwater, has become a public interest. African countries, such as Morocco, are facing several problems of lake pollution mainly due to the increase of human population, and the use of fertilizers and pesticides, which induces an alteration of water quality leading to severe effects such as eutrophication, fish mortality, ecosystem imbalance.., because lakes are lentic ecosystems, unlike rivers and oceans. Therefore, water quality monitoring has a high priority to ensure the protection of lake ecosystems and subsequently maintain an ecological balance of fish species, a biodiversity of fauna, and a healthy diet for local populations.

Our country has experienced a great diversity of natural lakes that have strategic importance as water resources, but also as remarkable aquatic environments related to aquifers and surface waters [3], but these lakes are vulnerable to pollution and anthropogenic pressures. Several studies have been done on the lakes of Morocco (Dayet Aoua [4], Afenourir Lake [5], Ouiouane Lake

\footnotetext{
* Corresponding author: sara.elg2014@gmail.com
} 
[6], etc.) are reporting that the lakes suffer from the pollution that is caused by human beings, as a result of human activity various pollutants emitted in the atmosphere fall into surface water through the cycle in nature [7]. The pollution of water basins distorts their self-purification ability and the contaminant accumulation is observed [8]. So we can say that human activities are a major factor determining the quality of the surface, through effluent discharges, use of agricultural chemicals, eroded soils....

Several previous studies [9] and [10] have evaluated the physico-chemical and metallic quality of lake dayet Er-Roumi's water. These studies have shown that Dayet Er-Roumi lake has a strong mineralization (a high salinity, with a dominance of chlorides), and significant metal pollution ( $\mathrm{Al}, \mathrm{Mn}$, and $\mathrm{Pb} . .$.$) , which reflects the$ direct influences of anthropogenic activity (intensive and uncontrolled use of phytosanitary products, wastewater, and domestic discharges...) on the ecological quality of the lake, which requires a complete diagnosis of the current situation and rigorous monitoring of its evolution.

The pollution of this lake has attracted the attention of water management researchers and decision-makers. To contribute to the understanding of lake functioning, our study aimed at evaluating and tracking the main components of the water to determine the ecological state of the lake, taking into consideration spatial and temporal variations. This study was conducted during the winter to estimate and quantify inputs, and during the summer when Dayet Er-Roumi's water level is low.

\section{Material and Methods}

\subsection{Description of the study area (sampling site)}

The site Dayet Er-Roumi $\left(33^{\circ} 45^{\prime} \mathrm{N}-06^{\circ} 12^{\prime} \mathrm{W}\right)$ is located on the alluvial coastal plain between Rabat to the West and the Middle Atlas Mountains to the East, situated on the territory of three rural communes: Ait Ouribel, Ait Ouahi, and Ait Houderrane. It is characterized by a semiarid climate with a maximum summer temperature of $38^{\circ} \mathrm{C}$, a minimum winter temperature of $7^{\circ} \mathrm{C}$, and a Mediterranean rainy regime. It has $2 \mathrm{~km}$ long and $400 \mathrm{~m}$ to $700 \mathrm{~m}$ wide, with an area of about 90 ha and a maximum depth of $13.5 \mathrm{~m}$ in the center (according to the National Center for Information Exchange on Biodiversity of Morocco [11]), This lake is feed by groundwater and two tributaries (Figure 1).

\subsection{Choice of stations and sampling}

The choice of sampling sites has been made according to the juxtaposed activities; in total, there are seven sampling stations (S1-S7), five points in the lake (S1-S5) are representing the areas that more likely to be affected by human activities (housing, hotel, etc.) and the other two points chosen are representing the lake's tributaries (Figure 1).
The water samples were taken by a Van d'Horn bottle at different depths to obtain a composite sample, the sampling was carried out during two seasons, winter and summer, of 2019 year.

The unstable parameters such as Conductivity, temperature, dissolved oxygen, and $\mathrm{pH}$ were measured in situ by a multiparameter instrument. The samples were collected in sterilized polythene bottles of one liter's capacity, kept in a cooler at $4{ }^{\circ} \mathrm{c}$, and transported to the laboratory for analysis of other physicochemical parameters (orthophosphates, nitrate, and chlorides). The analysis methods used are those of Rodier (1996) [12] and Afnor (1997) [13].

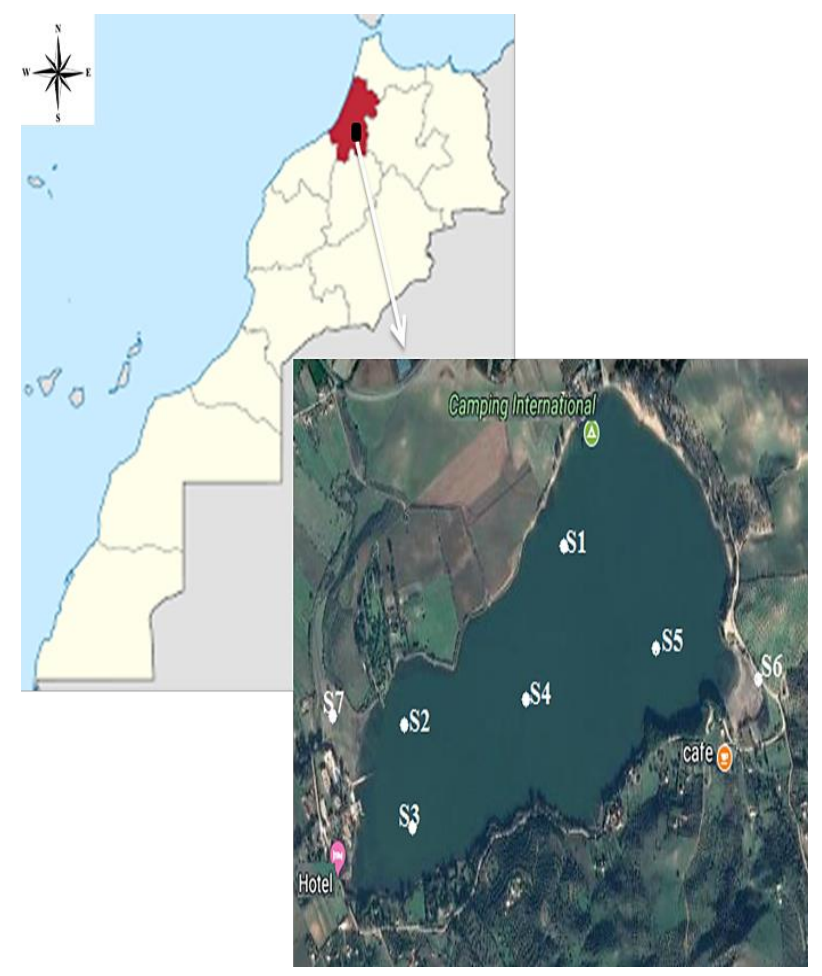

Fig. 1. Study area and location of sampling stations.

\subsection{Data treatment by statistical method}

For a better results interpretation, we relied on statistical analyses: SPSS (ANOVA and PCA).

ANOVA's analysis is used to test if there's a presence of significant differences or not between averages; it's also used to compare averages and the relative variance between them. Principal Component Analysis (PCA) is a descriptive multidimensional statistical method that can be used as a tool to assist the interpretation of a data matrix [14]. This method makes it possible to evaluate, synthesize and classify a large number of data, in order to extract the main factors that are at the origin of the simultaneous evolution of the variables and their proper relationships [15].

So the PCA is applied to establish relationships between the stations on the first hand and between the different parameters measured on the other hand, and to identify potential pollution and its characteristic elements. 


\section{Results and discussion}

\subsection{Spatio-temporal variation of physico- chemical parameters}

\subsubsection{Variation in situ of parameters $(\mathrm{pH}$, temperature, dissolved oxygen and electrical conductivity)}

The $\mathrm{pH}$ measures the concentration of $\mathrm{H}^{+}$ions in water, this parameter has a main role in physicochemical equilibrium. According to fig 2 , the $\mathrm{pH}$ values vary between 7.71 and 9.81 in the stations sampling.

The lower $\mathrm{pH}$ values were observed during the summer season and the higher values during the winter season due to precipitation. From these results we concluded that the $\mathrm{pH}$ exceeds the recommended standards [16] and [17], these high $\mathrm{pH}$ values indicate that the lake waters are very alkaline.

Water's temperature plays an important role in modifying chemical and physical properties as well as biological reactions. In our study, temperatures fluctuate between a minimum value of $14.36^{\circ} \mathrm{C}$ during winter and a maximum value of $23.62{ }^{\circ} \mathrm{C}$ in summer (fig 2). Normal seasonal variations were observed (an increase in temperature during the summer and vice versa). Our results show that the average water temperature is good and does not exceed the recommended standards [16] and [17].

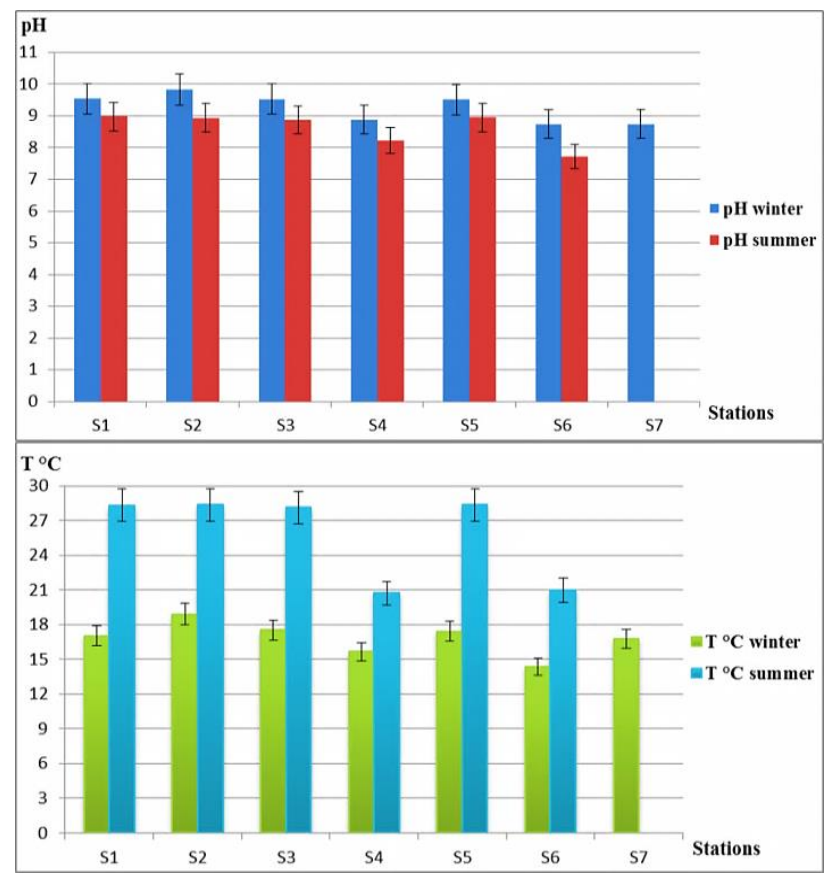

Fig. 2. Spatio-temporal variation of $\mathrm{pH}$ and temperature

Dissolved oxygen (DO) is an essential parameter in the functioning of aquatic ecosystems. In our study, dissolved oxygen's concentration varies between 4.41 and $13.88 \mathrm{mg} / \mathrm{l}$, it is higher during winter because a lower temperature promotes the dissolution of oxygen in water, and it is lower during summer (fig 3). These results show that the average DO content is good and also does not exceed the recommended standards [16] and [17].

Concerning the electrical conductivity, it varies between 1678.33 and $4375.5 \mu \mathrm{s} / \mathrm{cm}$, the maximal values were recorded during summer (maximal value at the tributary (S6)) generated by an important anthropogenic activities, the minimal values were observed during winter due to the precipitation that led to a phenomenon of water dilution. From fig 3, we conclude that the electrical conductivity greatly exceeds the recommended standards [16] and [17]. Waters of dayet Er-Roumi Lake are highly mineralized.

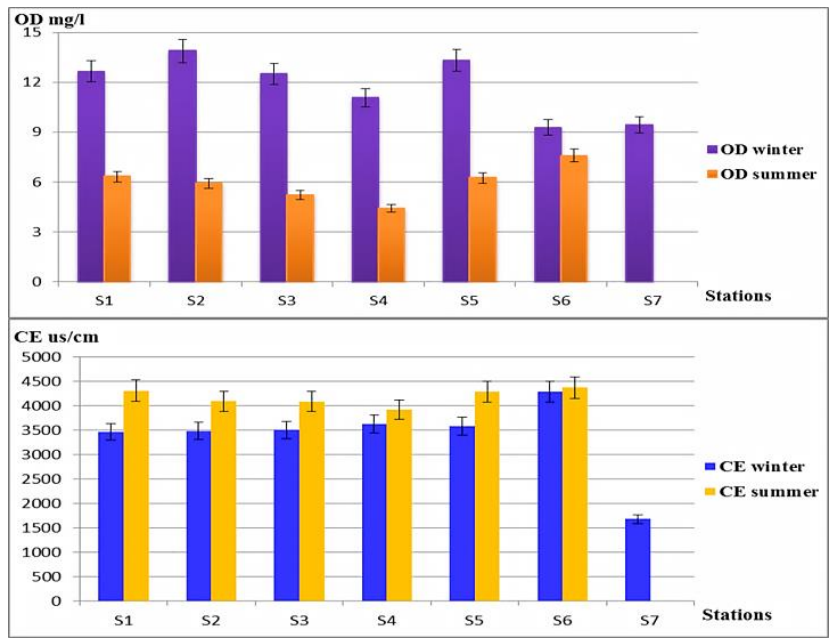

Fig. 3. Spatio-temporal variation of dissolved oxygen and electrical conductivity

\subsubsection{Variation of nitrates, chlorides and orthophosphates}

Nitrate concentrations range from 0.39 to $11.57 \mathrm{mg} / \mathrm{l}$. The monitoring at all stations reveals high concentrations during the winter season, particularly Station 7 is reaching a high concentration of $11.57 \mathrm{mg} / \mathrm{l}$ and exceeds recommended standards [16] and [17]. This high concentration is likely due to the leaching of agricultural land showing the intense anthropogenic activity in the region and its impact on lake water quality.

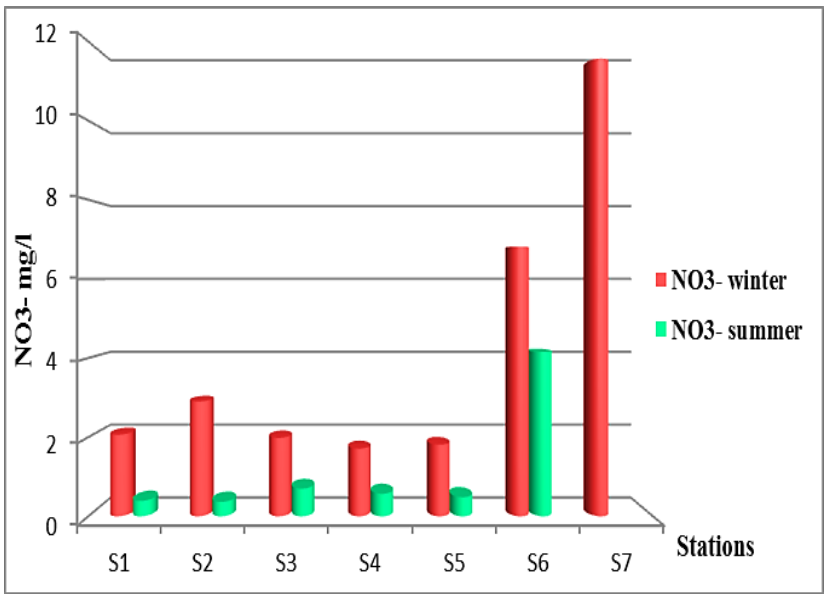

Fig. 4. Spatio-temporal variation of nitrates 
According to Figure 5, chloride values reveal significant concentrations over the two seasons, the high concentration of chlorides associated mainly with natural cross-fields (evaporite triassic rocks), not to mention the significant contribution of anthropogenic activities (agriculture, domestic waste, etc.), a slight decrease in chloride levels during winter is due to dilution after precipitation. Our results show that the average chloride concentration far exceeds the recommended standards [16] and [17]. These high concentrations can have adverse effects on the aquatic environment.

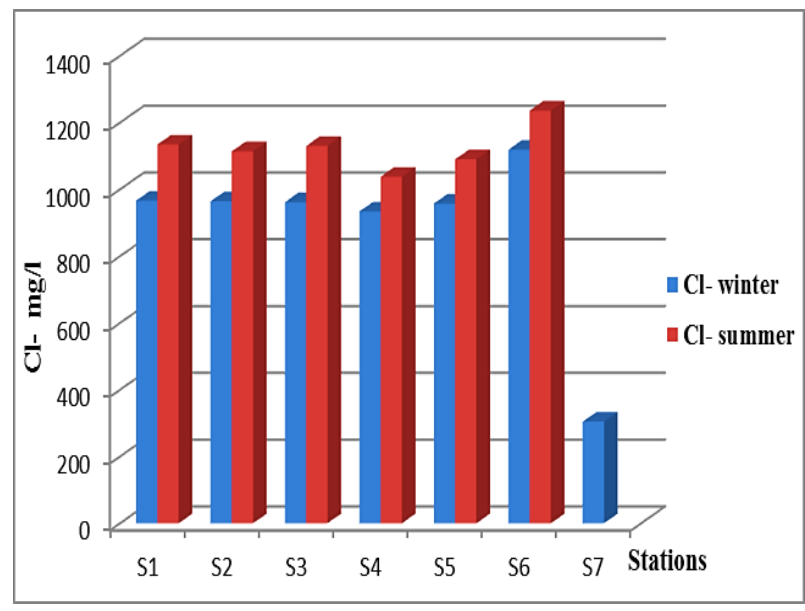

Fig. 5. Spatio-temporal variation of chlorides

Concerning orthophosphates, significant levels were recorded. The orthophosphates concentrations vary between 0.181 and $0.685 \mathrm{mg} / \mathrm{l}$. The maximal concentration $(0.685 \mathrm{mg} / \mathrm{l})$ was observed during summer, which indicates an anthropogenic activity (uncontrolled use of fertilizers and pesticides). The values recorded largely exceed the recommended standards [16] and [17]. These results show the vulnerability of the lake to extreme pollution (high concentration of orthophosphates can contribute to water eutrophication).

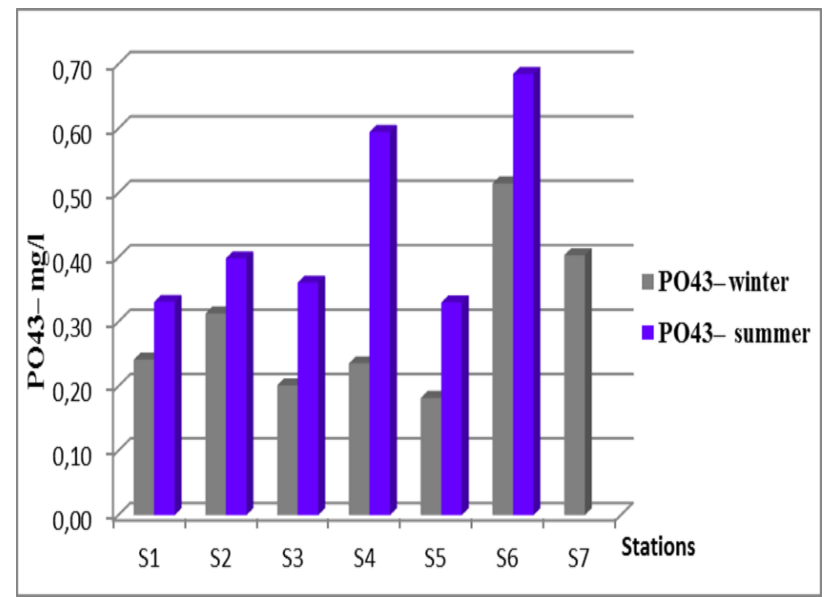

Fig. 6. Spatio-temporal variation of orthophosphates.

According to the results we conclude that the waters of lake Dayet Er-Roumi are polluted, the values of the electrical conductivity, nitrates, chlorides, and the orthophosphates largely exceed the standards [16] and [17], this suggests that a significant part of the ions can be from agricultural inputs such as chemical fertilizers, pesticides (insecticides, fungicides, etc.), and may also come from household waste and landfills, etc.

\subsection{Study of the evolution and variation of the physicochemical parameters}

In order to establish a relationship between the different physicochemical parameters, determine the ecological state of Lake, and to a better evaluation of anthropogenic activities effects on water's quality of Dayet Er-Roumi lake, a statistical treatment of PCA and ANOVA was applied to all the parameters.

The analysis was performed on a matrix of 7 samples (stations) and 7 variables $(\mathrm{pH}$, temperature, dissolved oxygen, electrical conductivity, nitrates, orthophosphates, and chlorides).

Table 1 and Figure 7, give the correlations between the variables, the factors, and the variables projection in the space of the axes F1 and F2.

Analysis of the factorial plan F1 and F2 shows that more than $91.36 \%$ are expressed. The F1 axis has a variance of $54.75 \%$ that is expressed with temperature, $\mathrm{pH}$, dissolved oxygen, and Nitrates. The F2 axis has a variance of $36.61 \%$ and consists of the following variables: Electrical conductivity, chlorides, and orthophosphates (Tab.1 and Fig.7).

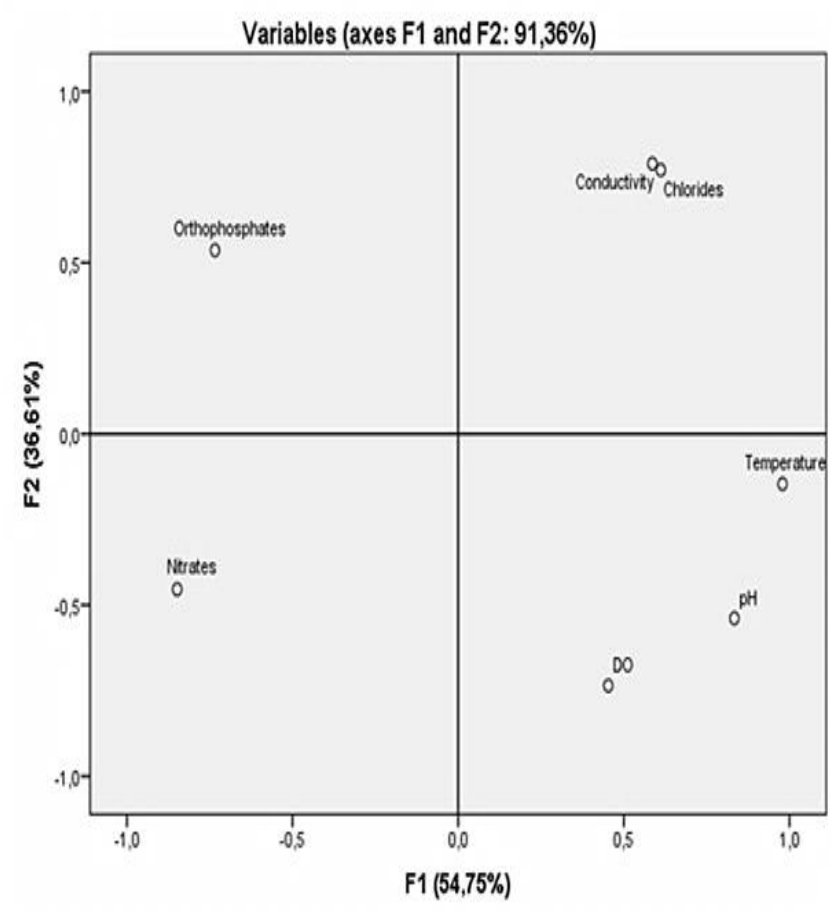

Fig. 7. Distribution of the physicochemical parameters according to the F1x F2 plan.

To assess the spatial distribution of physicochemical parameters we applied PCA to water samples from the Dayet Er-Roumi lake, which makes it possible to differentiate between three groups (Figure 8).

The first group (G1) is represented by 4 stations: S1, $\mathrm{S} 2, \mathrm{~S} 3$, and S5. All these stations are characterized by a very high value of temperature, $\mathrm{pH}$, and dissolved oxygen. 
The second group (G2) is represented by two stations S6 and S7 that are characterized by a strong mineralization, with a very high chloride and electrical conductivity values. This group indicates a very loaded water that could have harmful effects on fauna and flora as well.

Table 1. Correlation between variables and factors.

\begin{tabular}{|c|c|c|}
\hline \multirow{2}{*}{} & \multicolumn{2}{|c|}{ Components } \\
\cline { 2 - 3 } $\mathrm{pH}$ & $\mathrm{F} 1$ & $\mathrm{~F} 2$ \\
$\mathrm{0,217}$ & $-0,210$ \\
DO & $\mathbf{0 , 1 1 8}$ & $-0,287$ \\
Temperature & $\mathbf{0 , 2 5 5}$ & $-0,057$ \\
Conductivity & 0,153 & $\mathbf{0 , 3 0 8}$ \\
Nitrates & $\mathbf{- 0 , 2 2 1}$ & $-0,177$ \\
Orthophosphates & $-0,191$ & $\mathbf{0 , 2 0 9}$ \\
Chlorides & 0,160 & $\mathbf{0 , 3 0 1}$ \\
\hline
\end{tabular}

The third group (G3) includes station 7 (a tributary) is characterized by an average concentration of nitrate. This station is vulnerable to pollution by nitrate which is probably due to the uncontrolled use of fertilizers and pesticides.

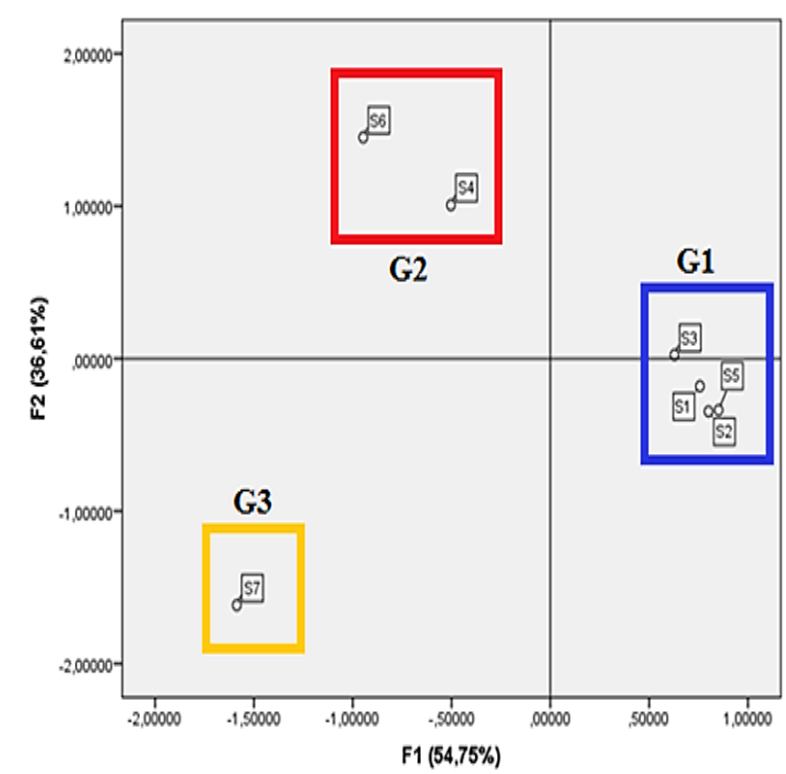

Fig. 8. Distribution of stations according to axes F1 and F2.

To evaluate the correlations between the different water physicochemical parameters, a statistical study by ANOVA was carried out. The results are represented in the second Table, according to this table, there are strong correlations between the different parameters:

Chlorides have a significant positive correlation with conductivity $(\mathrm{r}=0.996)$, temperature as well, has a significant positive correlation with $\mathrm{pH}(\mathrm{r}=0.901)$.
While a negative correlation has been observed between orthophosphate and $\mathrm{pH}(\mathrm{r}=-0.895)$, nitrate, and electrical conductivity $(\mathrm{r}=-0.812)$ and also between chlorides and nitrates ( $\mathrm{r}=-0.821)$ (Table 2$)$.

According to Figure 7 and Table 2, we note a strong significant correlation between chloride and electrical conductivity; however, an increase in electrical conductivity corresponds to a significant contribution of chlorides. These large concentrations are perhaps due to the geological nature of the crossed grounds, not to mention the participation of anthropic activities in this increase.

These high concentrations of chlorides in water can have acute and chronic toxic effects on aquatic organisms, while low concentrations can affect the structure of algal populations and communities in particular [18].

Similarly, there is a significant correlation between temperature and $\mathrm{pH}$, because these two parameters act in synergy, when there is a temperature increase, there is a decrease in $\mathrm{pH}$ and vice versa, we conclude that these correlations are very significant and witnesses on the affinity between these two elements.

Table 2. Correlation between physicochemical parameters of water

\begin{tabular}{|c|c|c|c|c|c|c|c|}
\hline & $\mathrm{pH}$ & $\mathrm{DO}$ & $\mathrm{T}^{\circ} \mathrm{C}$ & $\mathrm{EC}$ & $\mathrm{NO}_{3}{ }^{-}$ & $\mathrm{PO}_{4}{ }^{3-}$ & $\mathrm{Cl}^{-}$ \\
\hline $\mathrm{pH}$ & 1 & & & & & & \\
\hline $\mathrm{DO}$ & 0,749 & 1 & & & & & \\
\hline $\mathrm{T}^{\circ} \mathrm{C}$ & $\mathbf{0 , 9 0 1 * *}$ & 0,584 & 1 & & & & \\
\hline $\mathrm{EC}$ & 0,049 & $-0,227$ & 0,467 & 1 & & & \\
\hline $\mathrm{NO}_{3}{ }^{-}$ & $-0,472$ & 0,062 & $-0,735$ & $\mathbf{- 0 , 8 1 2 *}$ & 1 & & \\
\hline $\mathrm{PO}_{4}^{3-}$ & $\mathbf{- 0 , 8 9 5 * *}$ & $-0,544$ & $-0,753$ & 0,045 & 0,464 & 1 & \\
\hline $\mathrm{Cl}^{-}$ & 0,089 & $-0,208$ & 0,503 & $\mathbf{0 , 9 9 6 * *}$ & $\mathbf{- 0 , 8 2 1 *}$ & 0,027 & 1 \\
\hline
\end{tabular}

** The correlation is significant at the 0.01 level.

* The correlation is significant at the 0.05 level.

\section{Conclusion}

Nowadays, the protection of aquatic ecosystems is necessary for biodiversity and an ecological balance. The physicochemical study carried out on the waters of Dayet Er-Roumi Lake during the two seasons of 2019 (winter and summer), has revealed alarming values of chlorides, orthophosphates, nitrates, and conductivity that are largely exceeded recommended standards. The $\mathrm{pH}$ value shows that the lake waters are very alkaline.

The presence of high orthophosphates and nitrates concentrations clearly shows the intervention of anthropogenic activities in water's degradation quality, as a result of the uncontrolled fertilizers and pesticides use, domestic discharges, etc. The presence of the high chloride content is caused by the geological nature (the water crosses grounds constituted by triassic evaporitic rocks). 
According to these results, we found that the waters of Dayet Er-Roumi lake are deteriorated. An intervention of the concerned authorities and the management plan's establishment is necessary to conserve and maintain this SIBE.

\section{References}

1. D. Trakroo, and H. Tewari, Study of water quality by physicochemical analysis of a Himalayan lake of Uttarakhand, India Bonika Pant, Vibha Lohani, Malobica, Eco. Env. \& Cons. 23, ISSN 0971765X.( 2017)

2. O. I. Vandysh, "Zooplankton as an indicator of the state of lake ecosystems polluted with mining wastewater in the KolaPeninsula," Russian Journal of Ecology, vol. 35, no.2, p p.110-116, (2004).

3. L. Chillasse, M Dakki and M. Abbass, Ecological values and functions of the wetlands of the Middle Atlas (Morocco), Humedales Mediterráneos, (2001).

4. E. Abba , H. Nassali , M. Benabid, R. El Ayadi, and $\mathrm{H}$. El Ibaoui, Contribution to the physicochemical study of the Dayet Aoua lake ecosystem in Morocco, Afrique SCIENCE 04 (2008).

5. J. Griba , L. Nezha, S. Driss, M. Sadik, A. Serghini, M. Fekhaoui, Contribution to the study of the hydrochemical characteristics of the Ramsar site: Afenourir Lake, Morocco. Moroccan Journal of Chemistry ISSN: 2351-812X (2019).

6. Z. Idrissi chbihi, Study of the ageing of Lake Ouiouane in the Middle Atlas (Morocco), (2019).

7. F. Howladar, An assessment of surface water chemistry with its possible sources of pollution around the Barapukuria Thermal Power Plant impacted area, Dinajpur, Bangladesh. Groundwater Sustainable Dev., 5,38-48. (2017).

8. S. Nikolova, S. Lavrova-popova, Comparison of the physicochemical parametersof three different water bodies. Journal of Water and Environmental Sciences , Vol. 3, $\mathrm{N}^{\circ} 1$ (2019)

9. M. El Qryefy, M. Najy, D. Belghyti, J. Ouardi ,K. El Kharim, Evaluation of the physicochemical quality of Dayet Erroumi lake in low waterperiod(Khemisset, Morocco), In Proceedings of International conference Geo-IT and Water Resources $2020 \quad$ (GEOIT4W-2020). AlHoceima,Morocco, https://doi.org/10.1145/3399205.3399220.

10. S. El Ghizi, S. Hssaissoune, M. El Bouch, N. El Aadel, M. Sadik and M. Hasnaoui, Assessment Of Metalic Pollution In Water Of Lake Dayet Er-Roumi (Morocco). In Proceedings of International conference Geo-IT and Water Resources 2020 (GEOIT4W'2020). Al-Hoceima, Morocco, https://doi.org/10.1145/3399205.3399212.

11. M. MABUCHI, Datasheet on the SIBE (H9)Dayet Erroumi. National Center of Information exchange on the Biodiversity of Morocco, Convention on BiologicalDiversity,https://ma.chmcbd.net/manag_c ons/esp_prot/sibe_ma/sibe_cont_hum/dayetErroumi -h9-./si be_h9.(2006).

12. J. Rodier, Water analysis: Natural waters, wastewaters, and sea waters. 7th Ed. Dunod. Paris, (1996).

13. AFNOR, Qualité de l'Eau. Collection of French Environment Standards, (1997).

14. Y. Travi, J. Mudry, Method for the assessment and management of the nitrate risk in the basement aquifers of the Sahelian zone of West Africa. Hydrogeology review,1:13-21. (1997)

15. J. Biémi Contribution to the geological, hydrogeological, and remote sensing study of the Sub-Sahelian watersheds of the Precambrian basement of West Africa: Hydrostructural, hydrochemistry, and isotopy of discontinuous aquifers of the furrows and granitic areas of the Haute Marahoué (Ivory Coast). State Doctorate in Natural Sciences, National University of Côte d'Ivoire, p. 480. (1992).

16. Joint decree of the Minister of Equipment and the Minister responsible for regional development, town planning, housing and the environment $n{ }^{\circ} 1275-01$ of 10 chaabane 1423 (October 17, 2002) defining the quality grid of the surface water.

17. Joint order of the Minister responsible for Spatial Planning, Water, and the Environment $N^{\circ} 2027-03$ of 5 November 2003, setting the quality standards for fish waters. Official bulletin of November 5, (2003).

18. Health Canada. Canadian Environmental Protection Act, 1999, Priority Substances List, Assessment Report, Road Salts. 188 p, (2001). 